Mehdi KESHAVARZ-GHORABAEE, PhD

E-mail: m.keshavarz_gh@yahoo.com

Professor Maghsoud AMIRI, PhD

E-mail: amiri@ atu.ac.ir

Department of Industrial Management, Faculty of Management and

Accounting, Allameh Tabataba'i University, Tehran, Iran

Professor Edmundas Kazimieras ZAVADSKAS**, Dr.Sc.

E-mail: edmundas.zavadskas@vgtu.It (*corresponding author)

Department of Construction Management and Real Estate, Institute of Sustainable Construction, Faculty of Civil Engineering, Vilnius

Gediminas Technical University, Lithuania

Professor ZenonasTURSKIS, PhD

E-mail: zenonas.turskis@vgtu.It

Department of Construction Management and Real Estate, Institute of Sustainable Construction, Faculty of Civil Engineering, Vilnius

Gediminas Technical University, Lithuania

Professor Jurgita ANTUCHEVICIENE, PhD

E-mail: jurgita.antucheviciene@ vgtu.It

Department of Construction Management and Real Estate, Faculty of

Civil Engineering, Vilnius Gediminas Technical University, Lithuania

\title{
A COMPARATIVE ANALYSIS OF THE RANK REVERSAL PHENOMENON IN THE EDAS AND TOPSIS METHODS
}

Abstract. The rank reversal (RR) phenomenon could occur when new information about alternatives or criteria is added to the decision space of a discrete multi-criteria decision-making (MCDM) problem. If this addition leads to a change in the original rank of alternatives, the RR phenomenon occurs. In this study, we analyze the RR phenomenon in a new MCDM method called EDAS (Evaluation based on Distance from Average Solution). For this purpose, three RR indices are defined, and the efficiency of the EDAS method is compared with the TOPSIS method through a simulation-based analysis. The results show that the EDAS method is more efficient than the TOPSIS method with respect to the defined RR measures. TOPSIS.

Keywords: rank reversal, multi-criteria decision-making, MCDM, EDAS,

JELClassification:C02, C44, C61, C63.

1. Introduction

In real-world decision-making problems, we usually need to evaluate some alternatives with respect to multiple criteria. To deal with such problems, multi- 
Mehdi Keshavarz-Ghorabaee, Maghsoud Amiri, Edmundas Kazimieras Zavadskas, Zenonas Turskis, Jurgita Antucheviciene

criteria decision-making (MCDM) techniques and methods are very applicable. In recent decades, many researchers have studied on this field and proposed different MCDM methods such as Simple Additive Weighting (SAW) (MacCrimon, 1968), Analytic Hierarchy Process (AHP) (Saaty, 1980), ELimination Et ChoixTraduisant la REalité (ELECTRE) (Roy, 1968),Preference Ranking Organization Method for Enrichment of Evaluations (PROMETHEE) (Mareschal and Brans, 1992); Technique for Order of Preference by Similarity to Ideal Solution (TOPSIS) (Hwang and Yoon, 1981), VlseKriterijumskaOptimizacija I KompromisnoResenje (VIKOR) (Opricovic, 1998), etc. Interested readers are referred to some recent review papers about developments and applications of the methods in different fields. Various MCDM techniques and their applications were reviewed by Mardani et al. (2015), a comprehensive review of MCDM techniques in fuzzy environment was provided by Kahraman et al. (2015). Later, a broad overview of techniques with emphasis to application in supply chains was provided by KeshavarzGhorabaee et al. (2017a).

The rank reversal (RR) phenomenon is an important issue in decision-making processes with multiple criteria and could occur in different MCDM methods. Most of the studies in this field have been done on the AHP method (Barzilai and Golany, 1994; Schenkerman, 1994; Stam and Silva, 1997; Triantaphyllou, 2001; Wang and Elhang, 2006; Saaty and Sagir, 2009). Maleki and Zahir(2013) presented a comprehensive literature review of the rank reversal phenomenon in the AHP method. Some studies have also been performed on the RR phenomenon in the other MCDM methods including PROMETHEEand TOPSIS(Mareschalet al., 2008; García-Cascales and Lamata, 2012; Verly and De Smet, 2013). A usual form of this phenomenon occurs when a decision maker is confronted with one or more new alternatives that are not involved in the initial step of the decisionmaking process. The performance of the new alternative(s) is usually unpredictable, so the decision maker should be ready to handle the changes in final ranking of alternatives. The analysis of RR phenomenon can help the decisionmaker to deal with such a situation.

EDAS is a new MCDM method which proposed by KeshavarzGhorabaee et al. (2015). In this method, the desirability of an alternative is determined based on positive and negative distances of it from a reference solution called the average solution. This method has been applied and extended by some researchers since its introduction. Extensions of the method with grey numbers (Stanujkicet al., 2017), neutrosophic numbers (Peng and Liu, 2017), intuitionistic (Kahramanet al., 2017) and interval type-2 fuzzy sets (KeshavarzGhorabaeeet al., 2017b, 2017c) have recently been proposed. However, the RR phenomenon has not been examined in this method. Because of newness of the EDAS method, assessing different characteristics of it can be useful for future studies. In this study, the RR phenomenon is assessed based on addition of a new alternative. Three indices are defined to measure the frequency of occurrence, frequency of occurrence in first rank and intensity of occurrence of the RR phenomenon. An analysis is made by 


\section{A Comparative Analysis of the Rank Reversal Phenomenon in the EDAS and TOPSIS Methods}

simulation of the decision data in different numbers of alternatives and criteria, and the EDAS method is compared with the TOPSIS method with respect to the defined indices. The results show that the efficiency of the EDAS method is more than the TOPSIS method when the RR phenomenon occurs.

The rest of this paper is organized as follows. In Section 2, the steps of multicriteria decision-making process with the EDAS and TOPSIS methods are summarized. Also the framework of the analysis is described in this section. In Section 3, results of the analysis are presented. Finally, the conclusions are discussed in Section 4.

\section{Methodology}

Suppose that we have $n$ alternatives $\left(\mathcal{A}_{1}\right.$ to $\left.\mathcal{A}_{n}\right)$ and $m$ criteria $\left(\mathcal{C}_{1}\right.$ to $\left.\mathcal{C}_{m}\right)$, and the weight of each criterion $\left(w_{j}, j \in\{1,2, \ldots, m\}\right)$ is known. Accordingly, the decision-matrix is defined as follows:

$$
X=\left[\begin{array}{cccccc}
x_{11} & x_{12} & \ldots & x_{1 j} & \ldots & x_{1 m} \\
x_{21} & x_{22} & \ldots & x_{2 j} & \ldots & x_{2 m} \\
\vdots & \vdots & \ddots & \vdots & \ddots & \vdots \\
x_{i 1} & x_{i 2} & \cdots & x_{i j} & \cdots & x_{i m} \\
\vdots & \vdots & \ddots & \vdots & \ddots & \vdots \\
x_{n 1} & x_{n 2} & \cdots & x_{n j} & \cdots & x_{n m}
\end{array}\right]
$$

Based on the decision-matrix defined, the steps of the EDAS and TOPSIS methods are summarized in this section. Then, a framework is presented to perform the analysis of the RR phenomenon.

\subsection{The EDAS method}

As previously mentioned, this method is proposed by Keshavarz Ghorabaee et al. (2015). The EDAS method was applied to the inventory classification problem in its first introduction; however, the efficiency of this method for dealing with MCDM problems was also verified. In the EDAS method, the alternatives of an MCDM problem are evaluated based on positive and negative distances from an average solution. An alternative which has higher values of positive distances and lower values of negative distances from the average solution is a more desirable alternative according this method. The steps for using the EDAS method are as follows:

Step 1. Calculation of the elements of average solution $\left(g_{j}\right)$ :

$$
g_{j}=\frac{\sum_{i=1}^{n} x_{i j}}{n}
$$

Step 2. Determination of the positive $\left(\mathcal{P}_{i j}^{d}\right)$ and negative $\left(\mathcal{N}_{i j}^{d}\right)$ distances: 
Mehdi Keshavarz-Ghorabaee, Maghsoud Amiri, Edmundas Kazimieras Zavadskas, Zenonas Turskis, Jurgita Antucheviciene

$$
\begin{gathered}
\mathcal{P}_{i j}^{d}= \begin{cases}\frac{\max \left(0, x_{i j}-g_{j}\right)}{g_{j}} & \text { if } j \in B \\
\frac{\max \left(0, g_{j}-x_{i j}\right)}{g_{j}} & \text { if } j \in C\end{cases} \\
\mathcal{N}_{i j}^{d}= \begin{cases}\frac{\max \left(0, g_{j}-x_{i j}\right)}{g_{j}} & \text { if } j \in B \\
\frac{\max \left(0, x_{i j}-g_{j}\right)}{g_{j}} & \text { if } j \in C\end{cases}
\end{gathered}
$$

where $B$ and $C$ are the sets of benefit and cost criteria, respectively.

Step 3. Computation of the weighted summation of the distances:

$$
\begin{aligned}
& \mathcal{P}_{i}^{w}=\sum_{j=1}^{m} w_{j} \mathcal{P}_{i j}^{d} \\
& \mathcal{N}_{i}^{w}=\sum_{j=1}^{m} w_{j} \mathcal{N}_{i j}^{d}
\end{aligned}
$$

Step 4. Normalization of the values of the weighted summations:

$$
\begin{aligned}
& \mathcal{P}_{i}^{n}=\frac{\mathcal{P}_{i}^{w}}{\max _{k} \mathcal{P}_{k}^{w}} \\
& \mathcal{N}_{i}^{n}=1-\frac{\mathcal{N}_{i}^{w}}{\max _{k} \mathcal{N}_{k}^{w}}
\end{aligned}
$$

Step 5. Calculation of the appraisal score of each alternative:

$$
\mathcal{S}_{i}=\frac{1}{2}\left(\mathcal{P}_{i}^{n}+\mathcal{N}_{i}^{n}\right)
$$

Step 6. Rank the alternatives according to decreasing values of $\delta_{i}$.

\subsection{The TOPSIS method}

The TOPSIS method is a popular MCDM method which has been used in many real-world problems and extended in different uncertain environments. Interested readers are referred to review of the TOPSIS method by Behzadian et al. (2012). In this study, a classic version of this method presented by Hwang and Yoon (1981) is used for analysis. In the TOPSIS method, the evaluation process of alternatives is 


\section{A Comparative Analysis of the Rank Reversal Phenomenon in the EDAS and TOPSIS Methods}

made with respect to the distances from the ideal and anti-ideal solutions. The procedure of this method is presented in the following steps:

Step 1. Determination of the normalized values of the decision-matrix:

$$
\bar{x}_{i j}=\frac{x_{i j}}{\sqrt{\sum_{i=1}^{n} x_{i j}^{2}}}
$$

Step 2. Calculation of the weighted normalized values:

$$
\bar{x}_{i j}^{w}=w_{j} \times \bar{x}_{i j}
$$

Step 3. Determination of the ideal and anti-ideal solutions based on the weighted normalized values:

$$
\begin{aligned}
& I^{*}=\left\{\bar{x}_{1}^{w *}, \ldots, \bar{x}_{m}^{w *}\right\}=\left\{\left(\max _{i} \bar{x}_{i j}^{w} \mid j \in B\right),\left(\min _{i} \bar{x}_{i j}^{w} \mid j \in C\right)\right\} \\
& I^{-}=\left\{\bar{x}_{1}^{w-}, \ldots, \bar{x}_{m}^{w-}\right\}=\left\{\left(\min _{i} \bar{x}_{i j}^{w} \mid j \in B\right),\left(\max _{i} \bar{x}_{i j}^{w} \mid j \in C\right)\right\}
\end{aligned}
$$

where $B$ and $C$ are the sets of benefit and cost criteria, respectively.

Step 4. Calculation of the Euclidean distance of alternatives from the ideal $\left(D_{i}^{*}\right)$ and anti-ideal $\left(D_{i}^{-}\right)$solutions:

$$
\begin{aligned}
& D_{i}^{*}=\sqrt{\sum_{j=1}^{m}\left(\bar{x}_{i j}^{w}-\bar{x}_{j}^{w *}\right)^{2}} \\
& D_{i}^{-}=\sqrt{\sum_{j=1}^{m}\left(\bar{x}_{i j}^{w}-\bar{x}_{j}^{w-}\right)^{2}}
\end{aligned}
$$

Step 5. Calculation of the closeness coefficient $\left(C C_{i}\right)$ of each alternative:

$$
C C_{i}=\frac{D_{i}^{-}}{D_{i}^{*}+D_{i}^{-}}
$$

Step 6. Rank the alternatives in decreasing order of the closeness coefficient values. 
Mehdi Keshavarz-Ghorabaee, Maghsoud Amiri, Edmundas Kazimieras Zavadskas, Zenonas Turskis, Jurgita Antucheviciene

\subsection{RR phenomenon analysis}

In this study, to analyze the RR phenomenon, we assume a common situation in which a new alternative is added to the MCDM problem. In this regard, we define three indices as follows:

- Percentage of the Frequency of Occurrence (PFO): This index measures the ratio of the occurrence of the RR phenomenon in a given number of simulations.

- Percentage of the Frequency of Occurrence in First rank (PFOF): This index measures the ratio of the occurrence of the RR phenomenon in a given number of simulations where the first rank is changed.

- Intensity of Occurrence (IO):This index measures the intensity of the occurrence of the RR phenomenon in a given number of simulations by computing the average changes (AC) in different ranks. Suppose that we have an MCDM problem with n alternatives, and $R_{i}^{(1)}$ denote the original rank of $i$ th alternative and $R_{i}^{(2)}$ shows the rank of $i$ th alternative after occurrence of the RR phenomenon. Then the AC is computed as follows:

$$
A C=\frac{1}{n} \sum_{i=1}^{n}\left|R_{i}^{(1)}-R_{i}^{(2)}\right|
$$

According to the defined indices, the following algorithm is used to analyze the RR phenomenon:

Step 1: Define the number of alternatives $\left(n_{s}\right)$ and criteria $\left(m_{s}\right)$ for the simulation process.

Step 2: Start the simulation process, set iteration counter to one $(r=1)$, set the counter of the occurrence of the RR phenomenon to zero $(C O=0)$, set the counter of the occurrence of the RR phenomenon in the first rank to zero $(C O F=0)$, set the total value of the average changes to zero $(T A C=0)$, and define the total number of iterations (ITR).

Step 3: Define the first MCDM problem $\left(P_{1}\right)$ by generating a random decisionmatrix with the dimension $n_{s} \times m_{s}$ and elements in the range of $\alpha$ to $\beta$, and set the weight of all criteria to $\frac{1}{m_{s}}$.

Step 4: Define the second MCDM problem $\left(P_{2}\right)$ by adding a new alternative to $P_{1}$. This addition is made by generating a row with the dimension $1 \times m_{s}$ and elements in the range of $\alpha$ to $\beta$ and joining this row to the matrix of $P_{1}\left(P_{2}\right.$ has the dimension $\left.\left(n_{s}+1\right) \times m_{s}\right)$. 


\section{A Comparative Analysis of the Rank Reversal Phenomenon in the EDAS and TOPSIS Methods}

Step 5: Solve $P_{1}$ and $P_{2}$ by an MCDM method and determine the rank of each alternative. Suppose that $R_{i}^{(1)}$ and $R_{i}^{(2)}$ denote the rank of $i$ th in the first and second MCDM problems, respectively $\left(i=1,2, \ldots, n_{s}\right)$.

Step 6: If there is any difference between $R_{i}^{(1)}$ and $R_{i}^{(2)}\left(i=1,2, \ldots, n_{s}\right)$, increase the value of $C O$ by one $(C O=C O+1)$, calculate the value of $A C$ using Eq. (17), increase the value of $T A C$ by the calculated $A C(T A C=T A C+A C)$. If any change occurs in the first rank, increase $C O F$ by one $(C O F=C O F+1)$.

Step 7: Increase the iteration counter by one $(r=r+1)$. If the iteration counter is less than or equal to ITR $(r \leq I T R)$, go to Step 3, otherwise continue.

Step 8: Calculate the values of PFO, PFOF and IO as follow:

$$
\begin{aligned}
& P F O=\frac{C O}{I T R} \times 100 \\
& P F O F=\frac{C O F}{I T R} \times 100 \\
& I O=\frac{T A C}{I T R}
\end{aligned}
$$

\section{Comparative analysis}

Using the methodology of analysis of the RR phenomenon presented in the previous section, we make a comparison between the EDAS and TOPSIS methods in this section.

To perform the proposed algorithm, 64 modes are defined with respect to 8 values for the number of alternatives $\left(n_{s}=\{5,10,15,30,50,100,200,500\}\right)$ and 8 values for the number of criteria $\left(m_{s}=\{5,10,15,30,50,100,200,500\}\right)$, and the simulation is run for ITR $=10000$ times with the values $\alpha=1$ and $\beta=100$. Therefore $64 \times 10000=640000 \mathrm{MCDM}$ problems are solved using the EDAS and TOPSIS methods.

Based on the proposed algorithm and Eqs. (18) to (20), the values of PFO, PFOF and IO are determined in each mode of each method. Table 1 shows the values of PFO for the EDAS and TOPSIS methods.

According to Table 1, the values of PFO in the EDAS method is lower than or equal to the values of PFO in the TOPSIS method in all modes. Accordingly, we can say that the efficiency of the EDAS method is more than the TOPSIS method with respect to this index. Fig. 1 shows the variation of this index in $n_{s}=$ 
Mehdi Keshavarz-Ghorabaee, Maghsoud Amiri, Edmundas Kazimieras Zavadskas, Zenonas Turskis, Jurgita Antucheviciene

5regarding changes in the number of criteria, and Fig. 2 represents the variation of PFO in $m_{s}=5$ concerning changes in the number of alternatives.

Table 1. The values of PFO for the EDAS and TOPSIS methods.

\begin{tabular}{|c|c|c|c|c|c|c|c|c|c|}
\hline & \multirow[b]{2}{*}{$n_{s}$} & \multicolumn{8}{|c|}{$m_{s}$} \\
\hline & & 5 & 10 & 15 & 30 & 50 & 100 & 200 & 500 \\
\hline \multirow{8}{*}{ 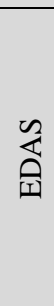 } & 5 & 27.68 & 29.95 & 30.25 & 31.26 & 31.81 & 32.4 & 32.24 & 33.08 \\
\hline & 10 & 51.64 & 54.61 & 54.47 & 55.89 & 56.41 & 57.27 & 56.99 & 56.89 \\
\hline & 15 & 67.87 & 68.7 & 70.86 & 72.14 & 71.42 & 72.39 & 71.98 & 72.78 \\
\hline & 30 & 89.19 & 91.01 & 91.63 & 92.61 & 92.7 & 92.51 & 92.55 & 92.72 \\
\hline & 50 & 97.29 & 97.82 & 98.24 & 98.34 & 98.62 & 98.74 & 98.76 & 98.62 \\
\hline & 100 & 99.78 & 99.95 & 99.95 & 99.93 & 99.97 & 100 & 100 & 100 \\
\hline & 200 & 99.88 & 99.99 & 100 & 100 & 100 & 100 & 100 & 100 \\
\hline & 500 & 100 & 100 & 100 & 100 & 100 & 100 & 100 & 100 \\
\hline \multirow{8}{*}{$\begin{array}{l}\tilde{n} \\
\tilde{\tilde{n}} \\
\stackrel{0}{H}\end{array}$} & 5 & 35.65 & 39.97 & 41.7 & 42.71 & 42.99 & 43.83 & 44.25 & 44.15 \\
\hline & 10 & 62.66 & 69.22 & 70.43 & 72.03 & 73.45 & 73.23 & 73.09 & 74.37 \\
\hline & 15 & 77 & 83.12 & 84.2 & 85.64 & 86.64 & 86.44 & 87.04 & 87.68 \\
\hline & 30 & 93.53 & 96.8 & 97.42 & 98.14 & 98.17 & 98.63 & 98.58 & 98.56 \\
\hline & 50 & 98.06 & 99.66 & 99.75 & 99.84 & 99.86 & 99.88 & 99.93 & 99.92 \\
\hline & 100 & 99.86 & 99.98 & 100 & 100 & 100 & 100 & 100 & 100 \\
\hline & 200 & 99.94 & 100 & 100 & 100 & 100 & 100 & 100 & 100 \\
\hline & 500 & 100 & 100 & 100 & 100 & 100 & 100 & 100 & 100 \\
\hline
\end{tabular}

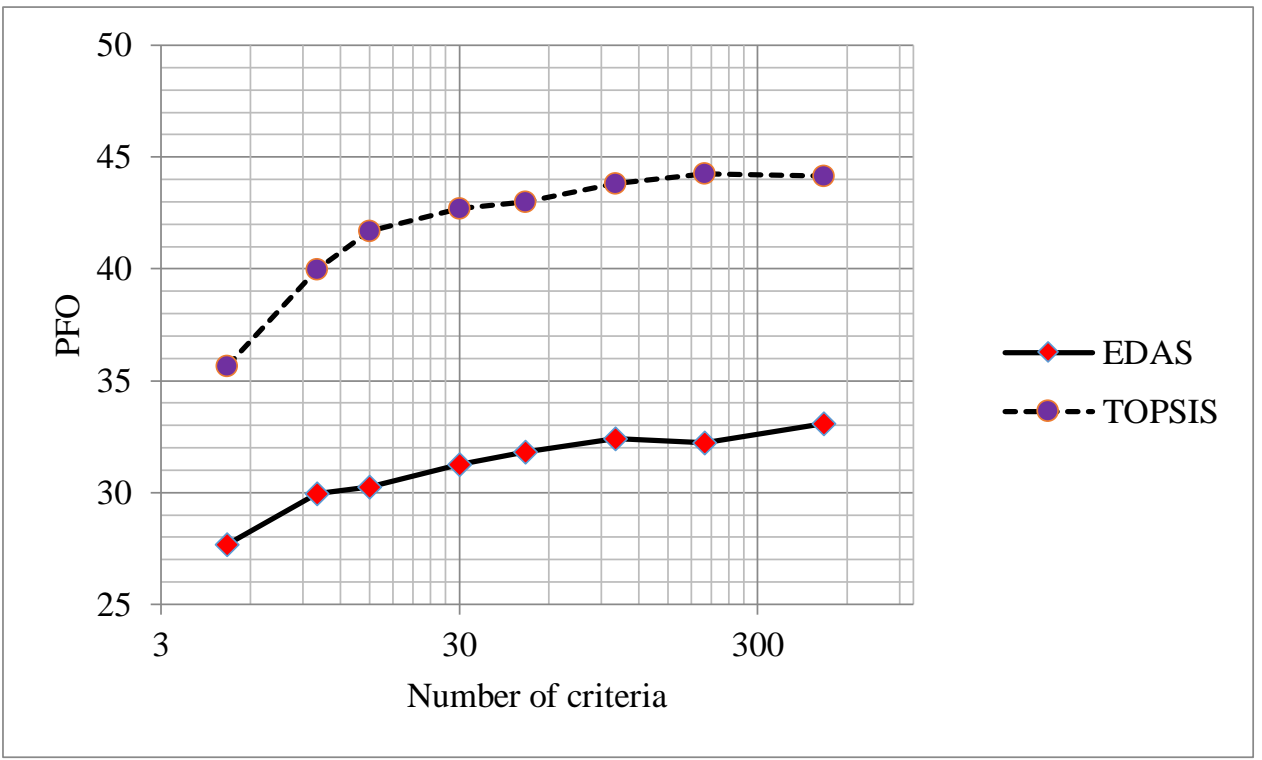

Figure 1. Variation of PFO in $n_{s}=5$.

It can be seen that the value of the PFO increase when we have higher number of alternatives and/or criteria. However, if we have more than 50 alternatives, the 
A Comparative Analysis of the Rank Reversal Phenomenon in the EDAS and TOPSIS Methods

possibility of the occurrence of RR phenomenon is very high in both the EDAS and TOPSIS methods.

In Table 2, the values of PFOF for the EDAS and TOPSIS methods can be seen.

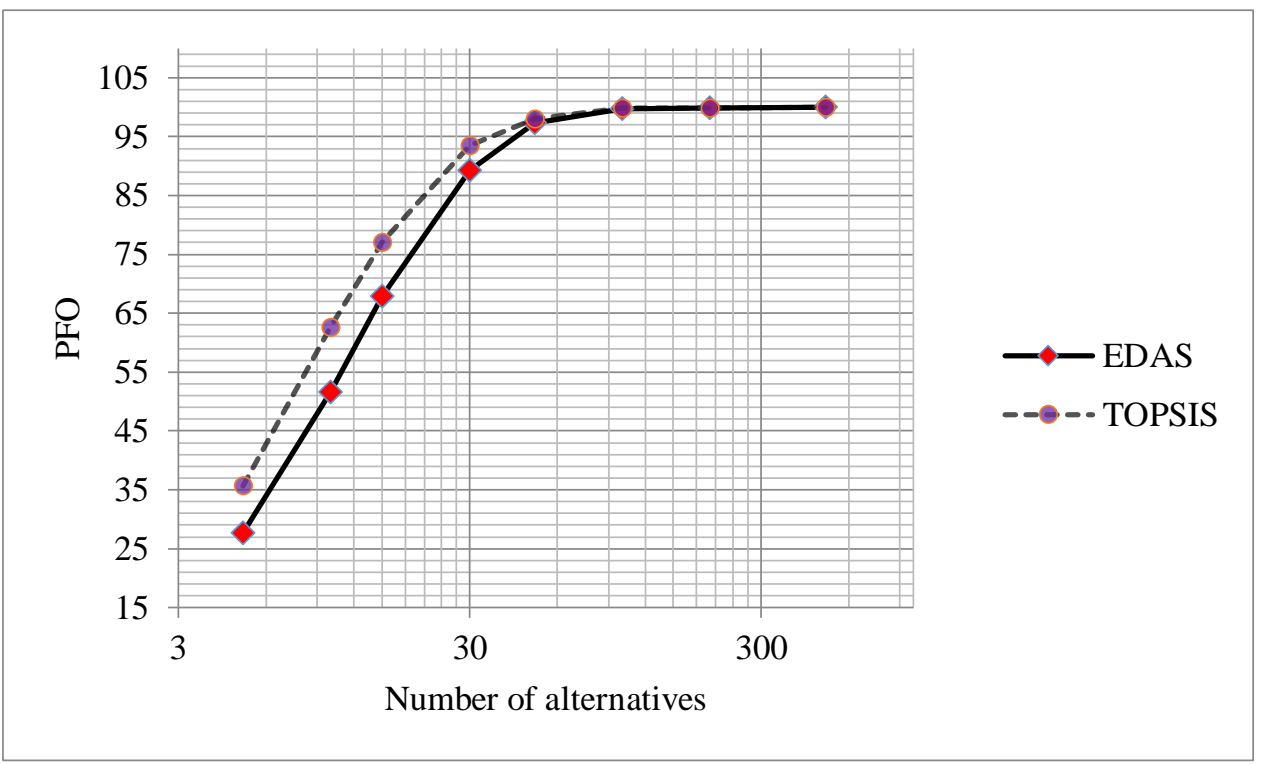

Figure 2. Variation of PFO in $m_{s}=5$.

Table 2. The values of PFOF for the EDAS and TOPSIS methods.

\begin{tabular}{|c|c|c|c|c|c|c|c|c|c|}
\hline & \multirow[b]{2}{*}{$n_{s}$} & \multicolumn{8}{|c|}{$m_{s}$} \\
\hline & & 5 & 10 & 15 & 30 & 50 & 100 & 200 & 500 \\
\hline \multirow{8}{*}{ 岕 } & 5 & 6.78 & 7.27 & 7.55 & 7.62 & 8.11 & 8.04 & 8.6 & 8.41 \\
\hline & 10 & 4.07 & 4.94 & 4.96 & 4.66 & 4.93 & 4.91 & 5.09 & 4.9 \\
\hline & 15 & 3.05 & 3.53 & 3.88 & 4.13 & 3.93 & 3.83 & 3.73 & 3.82 \\
\hline & 30 & 1.95 & 2.3 & 2.2 & 2.26 & 1.95 & 2.17 & 2.02 & 2.26 \\
\hline & 50 & 1.12 & 1.13 & 1.28 & 1.43 & 1.38 & 1.56 & 1.56 & 1.68 \\
\hline & 100 & 0.63 & 0.83 & 0.72 & 0.71 & 0.86 & 0.9 & 0.83 & 0.67 \\
\hline & 200 & 0.27 & 0.44 & 0.54 & 0.4 & 0.58 & 0.42 & 0.42 & 0.38 \\
\hline & 500 & 0.08 & 0.11 & 0.17 & 0.22 & 0.16 & 0.26 & 0.17 & 0.2 \\
\hline \multirow{8}{*}{$\begin{array}{l}\tilde{n} \\
\tilde{0} \\
0\end{array}$} & 5 & 8.61 & 10.18 & 10.94 & 11.02 & 11.6 & 11.37 & 11.94 & 11.71 \\
\hline & 10 & 5.9 & 7.1 & 7.11 & 7.49 & 7.76 & 7.72 & 8.05 & 8.33 \\
\hline & 15 & 3.91 & 5.32 & 5.57 & 5.94 & 6.08 & 6.19 & 5.76 & 6.38 \\
\hline & 30 & 2.06 & 2.52 & 2.8 & 3.27 & 3.75 & 3.23 & 3.25 & 3.78 \\
\hline & 50 & 1.18 & 1.95 & 2.1 & 2.03 & 2.43 & 2.46 & 2.35 & 2.24 \\
\hline & 100 & 0.79 & 0.93 & 1.25 & 1.21 & 1.13 & 1.33 & 1.47 & 1.2 \\
\hline & 200 & 0.33 & 0.5 & 0.65 & 0.58 & 0.52 & 0.62 & 0.68 & 0.86 \\
\hline & 500 & 0.11 & 0.13 & 0.23 & 0.24 & 0.19 & 0.3 & 0.22 & 0.29 \\
\hline
\end{tabular}


Mehdi Keshavarz-Ghorabaee, Maghsoud Amiri, Edmundas Kazimieras Zavadskas, Zenonas Turskis, Jurgita Antucheviciene

In Table 2, we can see that PFOF values of the EDAS method are lower than those of the TOPSIS method in most cases. Hence the EDAS method is more efficient than the TOPSIS method with regard to this index. For clarification, in Fig. 3 and Fig. 4, we depict the variation of PFOF with respect to changes in the number of alternatives and criteria. According to these figures, the value of PFOF has a direct relationship with the number of criteria and an inverse relationship with the number of alternatives.

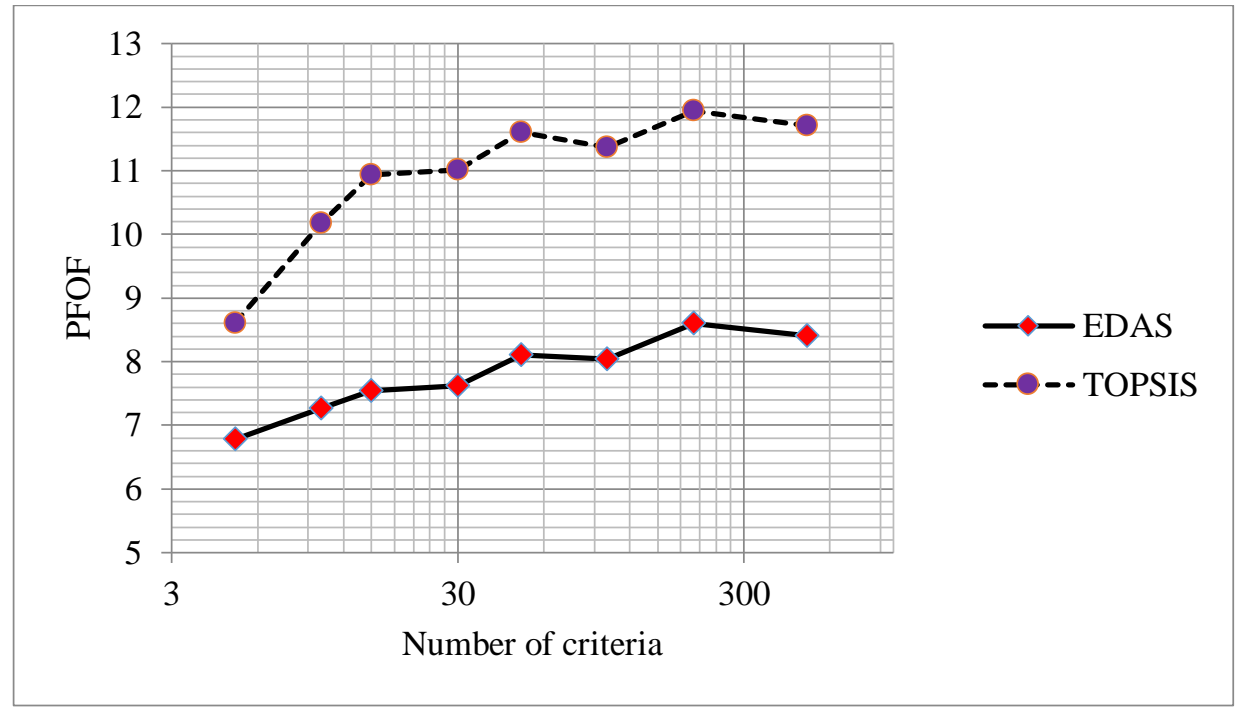

Figure 3. Variation of PFOF in $n_{s}=5$.

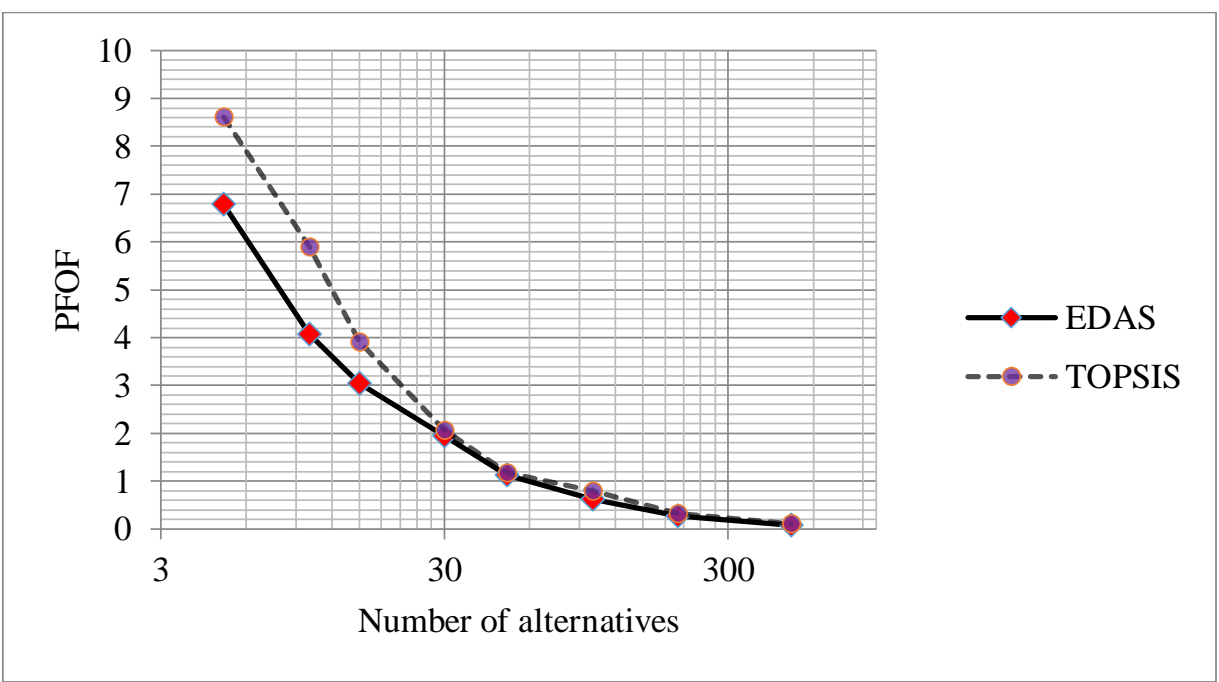

Figure 4. Variation of PFOF in $m_{s}=5$. 


\section{A Comparative Analysis of the Rank Reversal Phenomenon in the EDAS and TOPSIS Methods}

The values of the IO index, which shows the intensity of the occurrence of the RR phenomenon, are represented in Table 3. According to this table, the values of IO in the EDAS method are lower than the values of IO in the TOPSIS method in all modes, so the EDAS method behaves in a more efficient way with respect to this index. Fig. 5 and Fig. 6 are depicted to clarify the trend of variation of the IO index based on changes in the number of alternatives and criteria. It can be concluded that the value of IO has a direct relationship with both of the number of alternatives and criteria.

Table 3. The values of IO for the EDAS and TOPSIS methods.

\begin{tabular}{|c|c|c|c|c|c|c|c|c|c|}
\hline & \multirow[b]{2}{*}{$n_{s}$} & \multicolumn{8}{|c|}{$m_{s}$} \\
\hline & & 5 & 10 & 15 & 30 & 50 & 100 & 200 & 500 \\
\hline \multirow{8}{*}{ 峞 } & 5 & 0.1284 & 0.1425 & 0.1432 & 0.1475 & 0.1496 & 0.1530 & 0.1508 & 0.1562 \\
\hline & 10 & 0.1510 & 0.1607 & 0.1592 & 0.1641 & 0.1645 & 0.1659 & 0.1645 & 0.1663 \\
\hline & 15 & 0.1589 & 0.1629 & 0.1676 & 0.1686 & 0.1676 & 0.1695 & 0.1698 & 0.1695 \\
\hline & 30 & 0.1666 & 0.1732 & 0.1733 & 0.1725 & 0.1735 & 0.1741 & 0.1722 & 0.1723 \\
\hline & 50 & 0.1695 & 0.1742 & 0.1769 & 0.1763 & 0.1749 & 0.1750 & 0.1759 & 0.1728 \\
\hline & 100 & 0.1716 & 0.1770 & 0.1784 & 0.1788 & 0.1769 & 0.1750 & 0.1750 & 0.1745 \\
\hline & 200 & 0.1725 & 0.1789 & 0.1799 & 0.1788 & 0.1774 & 0.1769 & 0.1771 & 0.1759 \\
\hline & 500 & 0.1720 & 0.1769 & 0.1799 & 0.1773 & 0.1764 & 0.1775 & 0.1768 & 0.1763 \\
\hline \multirow{8}{*}{$\begin{array}{l}\tilde{n} \\
\tilde{0} \\
\hat{\theta}\end{array}$} & 5 & 0.1742 & 0.2029 & 0.2098 & 0.2157 & 0.2174 & 0.2215 & 0.2241 & 0.2245 \\
\hline & 10 & 0.2091 & 0.2389 & 0.2456 & 0.2497 & 0.2594 & 0.2591 & 0.2592 & 0.2646 \\
\hline & 15 & 0.2207 & 0.2453 & 0.2534 & 0.2623 & 0.2657 & 0.2676 & 0.2667 & 0.2702 \\
\hline & 30 & 0.2229 & 0.2492 & 0.2627 & 0.2652 & 0.2692 & 0.2749 & 0.2744 & 0.2762 \\
\hline & 50 & 0.2260 & 0.2518 & 0.2601 & 0.2666 & 0.2705 & 0.2721 & 0.2744 & 0.2750 \\
\hline & 100 & 0.2282 & 0.2513 & 0.2571 & 0.2652 & 0.2676 & 0.2696 & 0.2713 & 0.2713 \\
\hline & 200 & 0.2276 & 0.2508 & 0.2586 & 0.2645 & 0.2658 & 0.2684 & 0.2694 & 0.2699 \\
\hline & 500 & 0.2280 & 0.2513 & 0.2572 & 0.2634 & 0.2656 & 0.2667 & 0.2684 & 0.2684 \\
\hline
\end{tabular}


Mehdi Keshavarz-Ghorabaee, Maghsoud Amiri, Edmundas Kazimieras Zavadskas, Zenonas Turskis, Jurgita Antucheviciene
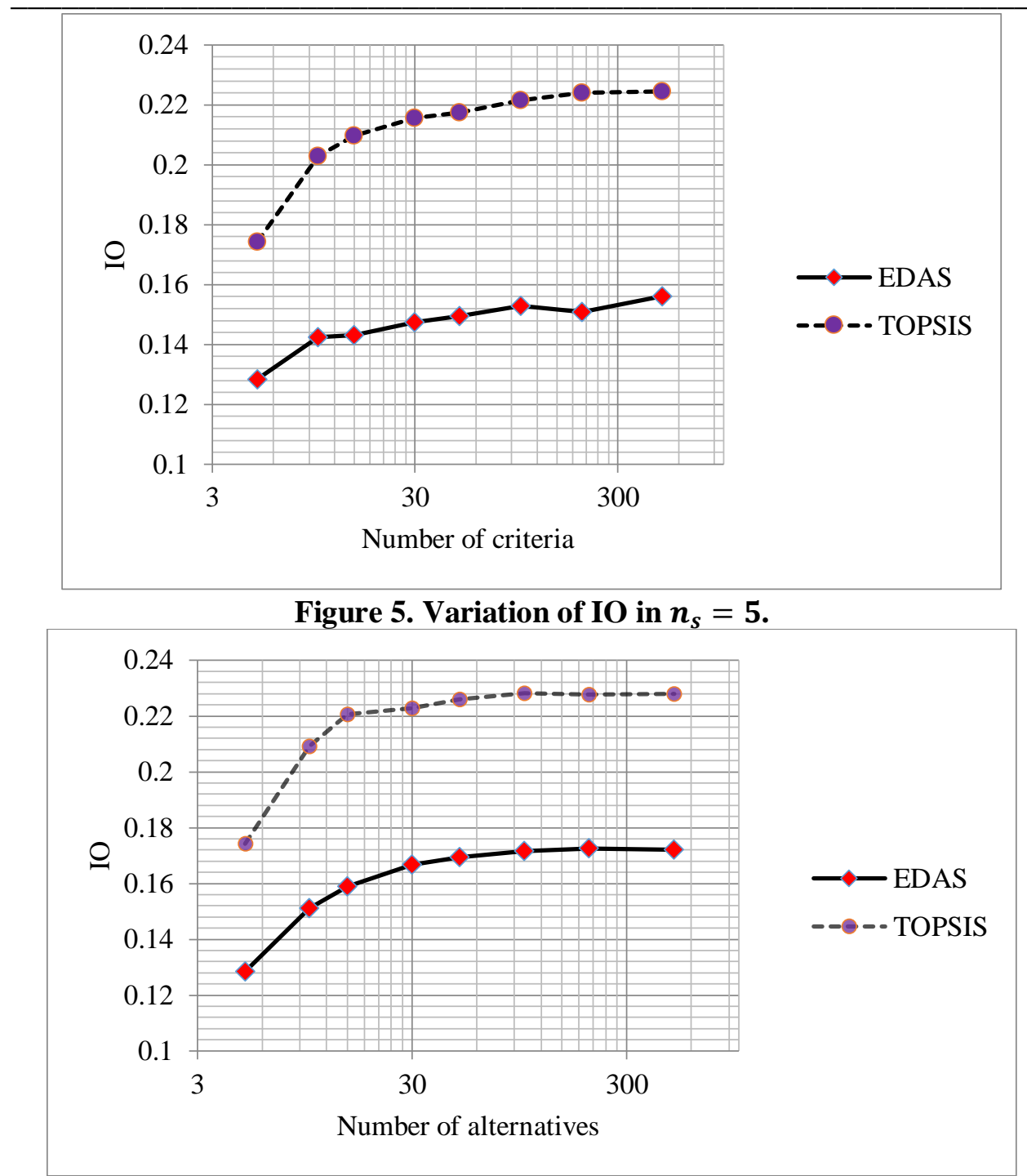

Figure 6. Variation of IO in $m_{s}=5$.

\section{Conclusions}

Multi-criteria decision-making methods are very useful to deal with the realworld decision-making problems. However, they have also some weaknesses to handle the problems. The rank reversal phenomenon is one of the important issues in MCDM methods. This phenomenon occurs when new information in decision process leads to some changes in the final decision. In this study, we have proposed three indices and a simulation-based algorithm to analyze the RR phenomenon. According to the proposed approach, the efficiency of EDAS as a 
A Comparative Analysis of the Rank Reversal Phenomenon in the EDAS and TOPSIS Methods

new MCDM method has been compared with the classic TOPSIS method. The results of the analysis show that the EDAS method is more efficient than the TOPSIS method in the three indices defined. On the other hand, the possibility of the occurrence of the RR phenomenon in both of the EDAS and TOPSIS methods is very high when we have more than 50 alternatives.

\section{REFERENCES}

[1] Barzilai, J.,Golany, B. (1994), AHP Rank Reversal, Normalization and Aggregation Rules. INFOR: Information Systems and Operational Research 32(2), 57-64;

[2] Behzadian, M., Otaghsara, S.K., Yazdani, M., Ignatius, J. (2012), A State-of the-Art Survey of TOPSIS Applications. Expert Systems with Applications 39(17), 13051-13069;

[3] García-Cascales, M.S.,Lamata, M.T. (2012), On Rank Reversal and TOPSIS Method. Mathematical and Computer Modelling 56(5), 123-132;

[4] Hwang, C. L., Yoon, K. (1981), Multiple Attributes Decision Making Methods and Applications: A State-of-the-Art Survey;Berlin, Hedelberg: Springer;

[5] Kahraman, C., Onar, S. C., Oztaysi, B. (2015), Fuzzy Multicriteria Decision-making: A Literature Review. International Journal of Computational Intelligence Systems, 8(4), 637-666;

[6] KeshavarzGhorabaee, M., Amiri, M., Zavadskas, E.K., Antucheviciene, J. (2017a), Supplier Evaluation and Selection in Fuzzy Environments: A Review of MADM Approaches. Economic Research-EkonomskaIstraživanja 30(1), 1073-1118;

[7] KeshavarzGhorabaee, M.,Amiri, M., Zavadskas, E.K., Turskis, Z., Antucheviciene, J. (2017b), A New Multi-Criteria Model Based on Interval Type-2 Fuzzy Sets and EDAS Method for Supplier Evaluation and Order Allocation with Environmental Considerations. Computers \& Industrial Engineering 112(Supplement C), 156-174;

[8] KeshavarzGhorabaee, M.; Amiri, M., Zavadskas, E.K., Turskis, Z. (2017c), Multi-criteria Group Decision-making Using an Extended EDAS Method with Interval Type-2 Fuzzy Sets. E\&MEkonomie a Management 20(1), 48-68;

[9] KeshavarzGhorabaee, M., Zavadskas, E. K., Oflat, L., Turskis, Z. (2015), Multi-criteria Inventory Classification Using a New Method of Evaluation Based on Distance from Average Solution (EDAS). Informatica 26(3), 435-451;

[10] MacCrimmon, K. R. (1968), Decision Making among Multiple Attribute Alternatives: A Survey and Consolidated Approach; RAND Memorandum, RM-4823-ARPA; 
Mehdi Keshavarz-Ghorabaee, Maghsoud Amiri, Edmundas Kazimieras Zavadskas, Zenonas Turskis, Jurgita Antucheviciene

[11] Maleki, H., Zahir, S. (2013), A Comprehensive Literature Review of the Rank Reversal Phenomenon in the Analytic Hierarchy Process. Journal of Multi-Criteria Decision Analysis 20(3-4), 141-155;

[12] Mardani, A., Jusoh, A., Md Nor, K., Khalifah, Z., Zakwan, N., Valipour, A. (2015), Multiple Criteria Decision-making Techniques and their Applications -A Review of the Literature from 2000 to 2014. Economic Research-EkonomskaIstraživanja 28(1), 516-571;

[13] Mareschal, B., Brans, J. P. (1992), PROMETHEE V: MCDM Problems with Segmentation Constrains; Brussels: UniversiteLibre de Brusells;

[14] Mareschal, B., De Smet, Y., Nemery, P. (2008), Rank Reversal in the PROMETHEE II Method: Some New Results. IEEE International Conference on Industrial Engineering and Engineering Management, IEEE, 959-963;

[15] Opricovic, S., Tzeng, G.-H. (2004), Compromise Solution by MCDM Methods: A Comparative Analysis of VIKOR and TOPSIS. European Journal of Operational Research 156(2), 445-455;

[16] Peng, X., C. Liu (2017), Algorithms for Neutrosophic Soft Decision Making Based on EDAS, New Similarity Measure and Level Soft Set. Journal of Intelligent \& Fuzzy Systems 32(1), 955-968;

[17] Roy, B. (1968), La method ELECTRE. Revue d'Informatique et. deRechercheOperationelle (RIRO) 8, 57-75;

[18] Saaty, T. L. (1980), The Analytic Hierarchy Process; New York: McGrawHill;

[19] Saaty, T.L.,Sagir, M. (2009), An Essay on Rank Preservation and Reversal. Mathematical and Computer Modelling 49(5), 1230-1243;

[20] Schenkerman, S. (1994), Avoiding Rank Reversal in AHP Decisionsupport Models. European Journal of Operational Research 74(3), 407419;

[21] Stam, A., Silva, A.P.D. (1997), Stochastic Judgments in the AHP: The Measurement of Rank Reversal Probabilities. Decision Sciences 28(3), 655-688;

[22] Stanujkic, D., Zavadskas, E.K., KeshavarzGhorabaee, M., Turskis, Z. (2017), An Extension of the EDAS Method Based on the Use of Interval Grey Numbers. Studies in Informatics and Control 26(1), 5-12;

[23] Triantaphyllou, E. (2001), Two New Cases of Rank Reversals when the AHP and Some of its Additive Variants Are Used that Do not Occur with the Multiplicative AHP. Journal of Multi-Criteria Decision Analysis 10(1), 11-25;

[24] Verly, C., De Smet, Y. (2013), Some Results about Rank Reversal Instances in the PROMETHEE Methods. International Journal of Multicriteria Decision Making 3(4), 325-345;

[25] Wang, Y.-M., Elhag, T.M.S. (2006), An Approach to Avoiding Rank Reversal in AHP. Decision Support Systems 42(3), 1474-1480. 